\title{
Coding and Analysing Behaviour Strategies of Instructors in University Science Laboratories to Improve Science Teachers Training
}

\author{
Patrick Osawaru Ajaja ${ }^{1}$ \\ ${ }^{1}$ Department of Science Education, Delta State University, Nigeria \\ Correspondence: Patrick Osawaru Ajaja, Department of Science Education, Delta State University, P.M.B. 1, \\ Abraka, Delta State, Nigeria. Tel: 234-803-723-0550. E-mail: osawaruajaja@yahoo.com
}

Received: September 22, 2012 Accepted: October 8, 2012 Online Published: November 27, 2012

doi:10.5539/ies.v6n1p63 URL: http://dx.doi.org/10.5539/ies.v6n1p63

\begin{abstract}
The intention of this study was to determine how science instructors in the university laboratories spend time on instruction. The study, was guided by three research questions and two hypotheses tested at 0.05 level of significance. The study employed a non-participant observation case study design. 48 instructors teaching lower and higher levels practical courses in Botany, Microbiology, Zoology, Chemistry, Physics, and Geology in Faculty of Science of Delta State University constituted the sample. A behaviour checklist called Science Laboratory Interaction Categories (SLIC) was the instrument used for data collection. A major finding of the study showed that science instructors spend most of the instructional time on; Demonstration of Procedure, Shows, Transmits, Listens and Non-lesson related behaviours resulting in less investigative teaching. Another finding of the study shows that among the six science disciplines the data revealed significant differences for all the instructor behaviours. It was concluded that the observation of what science instructors do in the university laboratories can be a source of valid information on how to improve science education in the universities and science teachers training for other levels of education and institutions.
\end{abstract}

Keywords: science, behaviour, laboratory, interaction and effective

\section{Introduction}

\subsection{Background of the Study}

Today's science education earnestly needs science teachers who are ready to have ideas about their teaching for the purpose of improvement and who possess the skills and materials to teach effectively. Most studies in science education have been concentrated on the evaluation of teaching at all levels through different methods. Literature on behaviour strategies show studies mainly on students' evaluation or rating of instructors and observational techniques of identifying effective teaching behaviours. Five key behaviours have been identified by researchers since the early 70s (Rosenshine, 1971; Good, 1986; Borich, 2004; Brophy, 1989; 2002; Brophy \& Cantrell, 1998/99; Dunkin and Biddle; 1974; Taylor, Pearson, Clark and Walpole, 1999; Teddlie and Stringfield, 1993; Walberg, 1986) as influencing effective science teaching. These include: clear presentation of instruction, use of different teaching methods, teacher spends most of the time in class teaching, engaging students in learning activities and determination of students' success in the class.

The literature on effective science teaching shows that it is not definitive on what constitutes an effective teaching. Ajaja $(1998,2005)$ while discussing the position held by (Dunkin \& Biddle 1974) suggested one reason for the inability of science education researchers to clearly define the meaning of effective science teaching which is generally accepted despite several years of research. What was found in literature was broad characteristics of effective science teaching varying to some extent from one author's definition to another. The suggestion is that the most clearly identified shortcoming of researchers in defining effective science teaching is their failure to observe teaching activities. It should be noted at this point that an objective, detailed and quantitative description of teachers and students interactions in science laboratories can be obtained correctly by systematic observational techniques. This entails the instructors' behaviours being coded and studied at different levels and situations depending on the purpose of the study.

Teaching is one of the very few occupations where very little effort is made to observe other professionals. Surgeons for example operate together and in the process students acquire skills and experiences in their field. Many 
teachers work in isolation. Once they start teaching, most teachers are deprived of the opportunity to observe other teachers at work.

Teachers can benefit immensely from the observation of other teachers, especially if the teaching situation is similar to their own. The opportunity to observe other teachers can lead to the identification of new ways of opening and closing of lessons; valuable resource units and books; assignments that seem to make a topic come alive; and ways to challenge students verbally without threatening them. Observation of other teachers may also identify behaviour that a teacher wants to eliminate or reduce in his own teaching.

Much emphasis in social learning theory is placed upon observational learning. Social learning theorists argue and present convincing data to illustrate that people can learn vicariously. Albert Bandura has been foremost among behaviourists stressing the potential of modeling for behaviour modification. Much behaviour, including very complex behaviour that can be shaped only through inefficient and time-consuming methods, can be taught quickly and easily through exposing the learner to a model who performs the behaviour. Bandura (1977) while discussing the relationship between learning theory and human behaviour noted that social learning theory approaches the explanation of human behaviour in terms of continuous reciprocal interaction between cognitive, behavioural, and environmental determinants. Continuing, he further affirmed that people and the environment in which they live, in a reciprocal way compliment one another.

Even with the above highlighted importance of observational studies in teaching and learning not much research efforts have been directed to this area and the findings of the few researches in the field are hardly applied in the teaching of science and learning. The situation therefore calls for a re-direction of science education research efforts to take care of this area for the purpose of effective teaching and learning of science.

Initial efforts on observational studies in science classrooms centered on: instructor behaviours being coded and described and sometimes classified with no attempts to induce significant changes to study the underlying conditions and establish relationships. It therefore became necessary to re-focus research efforts in this field to address this particular shortcoming. Again, is the fact that science teachers are trained by instructors in the university science laboratories and the much the teachers are able to impart on their students depends on the quality of their training. Correcting instructors' behaviour will improve the training of teachers. This informed the decision to carryout this study. Thus with the intention of assessing the behaviour strategies of instructors in university science laboratories, the areas of interest are verbal behaviours, manipulation of laboratory equipment, and interaction between teachers and students and among students. This study specifically investigated and analyzed specific instructor behaviours in 100 and 200 (lower) levels and 300 and 400 (higher) levels laboratories of six science disciplines Chemistry, Botany, Microbiology, Zoology, Geology and Physics at Delta State University, Abraka.

\subsection{Statement of the Problem}

This study grew from the fact that there is still limited knowledge of what goes on between instructors and students in science laboratories. This limited knowledge has influenced the inability of science educators to have clear and generally accepted view of what constitute an effective science teaching and laboratory behaviours. Another reason which propelled this study was that the few researchers in Nigeria who carried out similar studies in the field, in the past merely coded the behaviour of instructors studied, described and classified them without making any attempt to introduce changes, to study format with the intention to identify correlates. This gap is what this study intends to fill.

The problem of the study is therefore stated thus: will the evaluation of instructors' behaviours and their analysis provide clues for policy guide lines on instruction on how science instructors should dispose themselves in the laboratories for the purpose of proper instructional delivery?

\subsection{Research Questions}

The following three research questions were asked to properly focus the study.

1) What do instructors do in science laboratories?

2) Is there any difference in behaviour scores between laboratory instructors of lower and higher levels among the six science disciplines?

3) Do the mean behaviour score of instructors on specific items differ among the six science disciplines?

\subsection{Research Hypothesis}

These hypotheses were stated and tested at 0.05 level of significance.

Ho1.There is no significant difference in behaviour scores between laboratory instructors of lower and higher levels among the six science disciplines. 
Ho2. There is no significant difference in mean behaviour scores of instructors on specific items among the six science disciplines.

\section{Materials and Methods}

\subsection{Design of the Study}

A case study design was employed to study the behaviour patterns of instructors in science laboratories in Delta State University, Abraka. The study specifically investigated the behaviour patterns of instructors of lower levels (100 \& 200) and higher levels (300 \& 400) during laboratory classes in six science disciplines: Botany, Chemistry, Microbiology, Geology, Physics and Zoology. The non-participant observation design was the type of case study employed. This was appropriate since an observer merely sat in the laboratory to code the behaviour pattern of an instructor as the laboratory lesson goes on. As a rule, any study where the researcher only observes the characteristics of an individual unit of research interest, the design of such study is called case study (Johnson \& Christensen 2000).

\subsection{Population and Sample of the Study}

The population of the study consisted of all the laboratory instructors who teach the practical courses offered in Botany, Chemistry, Microbiology, Geology, Physics and Zoology departments in Delta State University.

The sample of the study consisted of 48 laboratory instructors. For each discipline, eight instructors were purposefully selected. Four of whom taught lower levels (100 \& 200) laboratory courses while the remaining four taught the higher levels $(300 \& 400)$ laboratory courses. These subjects were so selected because they were the ones available for the study. This sampling procedure was most convenient for the researcher since the problem of finding out who is to be selected did not exist.

The study was deliberately limited to one institution to remove the effects of intervening variables peculiar to different institutions from affecting the results. The pooling together of results of specific and different institutions with their peculiarities will produce a better picture of what goes on in the university laboratories than if one single study collected data from all universities at once and with varying intervening variables uncontrolled. This therefore calls for a replication of the study in other universities later.

\subsection{Instrument}

The instrument used for the study was a behaviour checklist called Science Laboratory Interaction Categories (SLIC) adapted by Ajaja (1998) from the work of Shymansk and Penick (1979). The checklist is an observational instrument designed mainly for coding the behaviour of instructors in science laboratories. The instrument is shown in appendix 1. Observers using the SLIC instrument code the behaviour of an instructor in a laboratory every 3-5 seconds using codes representing three dimensions of the interaction. The three dimensions are: (1) what is the specific nature of the behaviour being exhibited? (2) to whom is a specific behaviour being directed?; and (3) what is the sex of the student to whom the behaviours are being directed?

The SLIC consists of 15 specific categories of science teacher laboratory behaviours which represents the detailed structure of six broader strategies of teaching. These broad categories are: (1) Asking questions; (2) Giving directions; (3) Transmitting information; (4) Providing feedback; (5) Observing and gathering information; and (6) Administering programme or manipulating equipment. The detailed behaviours in the categories $(X, Q, D, G, S, T$, P, N, B, A, L, O, R, M, \& Z) of the SLIC are described below.

\section{Categories of the SLIC}

X Asks extended thought question; requires students to synthesize ideas; includes question designed to elicit predictions, hypotheses, explanations, or evaluations. E.g. explain, interpret, translate, summarize, analyze, detect differences and similarities.

Q Ask factual recall question; no student synthesis required, includes questions asked for descriptions of what was done or happened. E.g. name, define, state methods, and identify processes and structure.

D Demonstrates Procedure; any teacher manipulation to tell the student what to do or how to do an activity. E.g. calling students' attention to how he demonstrates an experiment which will guide in their experiments.

G Gives Direction; verbal behaviours which tell the student what to do or how to do, designed to redirect student behaviour. E.g. look at me, listen attentively and follow these directives in a sequential order.

S Shows illustrates; any teacher manipulation of equipment done for the purpose of transmitting non-directive information (not designed to tell students what to do or how to do an activity). E.g. teachers correction of apparatus set up by confused students during practical lesson. 
$\mathrm{T}$ Transmits information; verbally transmitted non-directive information without the use of manipulative materials. E.g. more reagents and materials are in preparatory room. Students who need more of them can ask from the laboratory attendant.

P Positive-reinforcement: positive evaluation of student behavior. E.g. good result, very good result, good management of time, efficient use of reagents.

N Negative reinforcement: negative evaluation of student behaviour. E.g. very poor work, waste of time and materials.

B Active Observation; receiving information from the student through the direct manipulation of or references to material or object. E.g. can I look at your results? Take your readings once again. Do your titration let me see how you obtained the results.

A Acknowledges student behaviour; non-evaluative statements or gestures used to indicate attentiveness to student behaviour, includes repeating or rephrasing student response. E.g. who made the statement? That answer he gave you is not entirely right. Can any of you give the correct answer?

L Listens to student; receiving information from student through discourse directed at the teacher. E.g. listening to students responses to questions asked by instructor.

O Passive observation; watching or listening to students in situations where teacher is not directly or actively involved. E.g. instructor watches as students carryout their experiments to find out how many of them are doing the right thing.

$\mathrm{R} \quad$ Reads and/or writes; any lesson related reading or writing done by the teacher, with or without students directly involved. E.g. instructor reading and marking students assignments and writing instructions for the next practical lesson.

M Get supplies; procurement of materials for use in the laboratory. E.g. instructor's provision of materials and equipment for practical lesson.

Z Non-lesson-related behaviours; any teacher behaviour which does not facilitate the activities or lesson taught. E.g. instructors discussion with colleagues on visit and has no business with the lesson.

The validity of the SLIC was first determined by a panel which consisted of three judges: a specialist in Science Education; an experienced laboratory instructor; and a Measurement and Evaluation expert. They mainly examined the contents of the instrument to find out if the objective of the study could be achieved with the instrument. That is generating data to determine the laboratory behaviours of instructors in university science laboratories. To make their job relatively easy, the research questions, research hypotheses and the draft of the SLIC were made available to all members of the panel for their comments. Few corrections were made on the instrument on receipt of the judges' comments. The second stage in determining the validity of the SLIC, was subjecting the instrument to a series of Factor Analysis - to determine its construct validity. This involves the use of the Extraction Method: Principal Component Analysis and Rotation Method - Quartimax with Kaiser Normalization. Specifically, to determine the construct validity using the Factor Analysis approach, the instrument which consisted of fifteen (15) items was used to code the laboratory behaviours of twenty (20) laboratory instructors who were not part of the sample of study by four (4) observers. On analysis of the coded behaviours of the instructors, the fifteen (15) items were retained haven met the recommended standard of initial Eigenvalues of at least 1.00. Based on this result, the fifteen (15) items were regarded as being valid and the instrument testing what it purports to be measuring.

The reliability of the SLIC was determined by using the inter-rater reliability approach. This involved the coding of the laboratory behaviours of five randomly selected science instructors in five departmental laboratories (Agric Science, Biology, Chemistry, Physics and Integrated Science) in College of Education, Agbor, by the four trained raters used for the study. This was followed by combining the ratings of the four raters and then applying the inter-rater reliability formula to analyse the collected data. This formula was adopted in line with the recommendations of Thorndike and Hagen (1997); Wiseman (1999); and Johnson \& Christensen (2000); that if several judges who have equal competence are available with the materials to be rated or equal familiarity with the ratee and the ratings are of a person, then a pooling of their ratings will produce a composite that is more reliable. The reliability index obtained on application of the inter-rater reliability formula was 0.83 indicating that the instrument was reliable.

\subsection{Training of Raters}

To code the instructors laboratory behaviours, the researcher recommended that observers (raters) should act as non-participant observers. To achieve this, the researcher and the four selected raters (observers) studied the items 
in the SLIC a week before the commencement of the study to mainly understand what to code as behaviour, how to code and where to code. It was recommended to the raters that eight instructors should be observed by each rater per week and for six weeks. This therefore means that each rater will observe all the selected instructors in all the selected science laboratories. Each of the science laboratory instructors should be observed for 30 minutes. This entail, that as the laboratory class progressed, using the SLIC checklist, each observer makes appropriate strokes next to the appropriate categories every five seconds. At the end of the lesson, the frequency of occurrence of the categories for each subject observed was recorded and documented.

\subsection{Data Collection Procedure}

The laboratory behaviours of 48 laboratory instructors of six science disciplines in Delta State University, Abraka were collected for six weeks using the Science Laboratory Interaction Categories (SLIC). The raters consisted of a team of five persons which included; the researcher and the four trained raters. Each of the selected science instructors was observed for 30 minutes. On weekly bases, and during laboratory lessons, each rater was assigned to one science discipline laboratory for the observation of eight (8) instructors. The researcher specifically observed the trained raters to identify difficulties encountered and offered clarifications where necessary. During the laboratory class, the raters made strokes next to the appropriate categories every five seconds on the SLIC for each science laboratory instructor observed. After a laboratory lesson, the frequency of occurrence of the categories for each subject observed was recorded. The average scores for all the individuals rated per discipline and per level were then noted, recorded and expressed in percentage in relation to time spent on observation.

Analysis of variance (ANOVA) statistic was used to test for significant difference between mean behaviour scores of instructors in lower and higher levels of laboratory classes among the six science disciplines. The ANOVA was also used to find out if there were significant differences in mean behaviour scores on specific behaviour item among the science laboratory instructors in the six science disciplines.

\section{Results}

Table 1. Percentage of Occurrence of Individual Instructor Behaviours in University Science Laboratories

\begin{tabular}{|c|c|c|c|c|c|c|c|c|c|c|c|c|c|}
\hline \multirow{2}{*}{\multicolumn{2}{|c|}{ Behaviours }} & \multicolumn{7}{|c|}{ LOWER LEVEL } & \multicolumn{5}{|c|}{ HIGHER LEVEL LORATORIES } \\
\hline & & $\begin{array}{c}\text { 吾 } \\
\text { ○े } \\
\mathrm{D}=4 \\
\mathrm{~N}=4\end{array}$ & 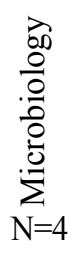 & $\begin{array}{c}\text { 兽 } \\
\frac{0}{\circ} \\
\stackrel{0}{N} \\
\mathrm{~N}=4\end{array}$ & 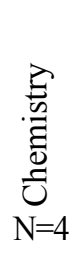 & $\begin{array}{l}\frac{0}{0} \\
\stackrel{0}{2} \\
\stackrel{2}{2}=4\end{array}$ & 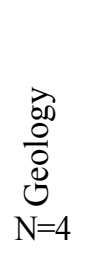 & $\begin{array}{c}\grave{\Xi} \\
\stackrel{\vec{J}}{0} \\
\stackrel{9}{0} \\
\mathrm{~N}=4\end{array}$ & $\begin{array}{l}\widehat{0} \\
0 \\
0 \\
0 \\
0 \\
0 \\
\stackrel{0}{0} \\
\sum_{N=4}\end{array}$ & $\begin{array}{c}\widehat{\mathrm{d}} \\
\stackrel{0}{\circ} \\
\stackrel{8}{0} \\
\mathrm{~N}=4\end{array}$ & 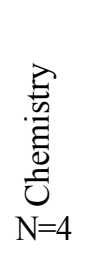 & 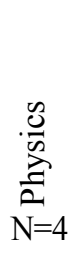 & 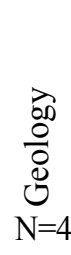 \\
\hline $\mathrm{X}$ & $\begin{array}{l}\text { Asks extended thought } \\
\text { questions }\end{array}$ & 1.6 & 0.6 & 0.6 & 0.1 & 0.0 & 0.2 & 0.2 & 0.1 & 0.1 & 0.3 & 0.1 & 0.0 \\
\hline Q & $\begin{array}{l}\text { Asks factual recall } \\
\text { questions }\end{array}$ & 3.8 & 3.9 & 1.9 & 2.7 & 2.8 & 2.2 & 1.0 & 1.0 & 1.3 & 4.3 & 3.4 & 0.8 \\
\hline $\mathrm{D}$ & $\begin{array}{l}\text { Demonstrates } \\
\text { procedures }\end{array}$ & 0.5 & 0.3 & 2.6 & 9.9 & 12.2 & 1.5 & 0.6 & 0.6 & 2.6 & 6.4 & 14.1 & 0.7 \\
\hline G & Gives direction & 0.7 & 1.1 & 3.7 & 7.8 & 7.0 & 3.4 & 0.4 & 2.1 & 5.1 & 6.2 & 3.3 & 1.1 \\
\hline $\mathrm{S}$ & Shows & 9.0 & 8.6 & 21.4 & 0.7 & 7.8 & 13.3 & 12.0 & 12.3 & 6.0 & 2.8 & 3.3 & 6.2 \\
\hline $\mathrm{T}$ & Transmits & 39.2 & 33.3 & 21.3 & 13.9 & 19.2 & 56.0 & 32.8 & 30.0 & 33.1 & 16.6 & 12.3 & 5.4 \\
\hline$P$ & Positive reinforcement & 0.7 & 1.4 & 0.4 & 0.1 & 0.1 & 0.8 & 2.3 & 0.1 & 0.2 & 0.1 & 0.3 & 0.0 \\
\hline $\mathrm{N}$ & $\begin{array}{l}\text { Negative } \\
\text { reinforcement }\end{array}$ & 0.3 & 0.6 & 0.3 & 0.3 & 0.4 & 0.2 & 0.1 & 0.5 & 0.4 & 0.6 & 0.2 & 0.2 \\
\hline
\end{tabular}




\begin{tabular}{lcccccccccccc}
\hline B Active observation & 4.9 & 8.9 & 8.2 & 6.4 & 8.4 & 1.5 & 4.0 & 7.4 & 6.3 & 12.6 & 14.0 & 5.5 \\
A Acknowledges & 4.7 & 4.2 & 1.6 & 2.2 & 4.1 & 1.7 & 2.9 & 3.4 & 2.4 & 2.7 & 3.2 & 0.7 \\
L Listens & 16.9 & 18.1 & 6.1 & 10.7 & 9.6 & 5.5 & 15.9 & 18.9 & 10.4 & 17.8 & 6.1 & 4.3 \\
O Passive observation & 4.1 & 3.9 & 4.7 & 17.0 & 9.7 & 4.9 & 17.7 & 12.0 & 2.9 & 8.1 & 19.3 & 11.3 \\
R Reads and/or writes & 2.7 & 2.8 & 0.5 & 17.8 & 1.5 & 4.5 & 0.4 & 3.6 & 2.2 & 3.9 & 3.5 & 26.1 \\
M Moves & 4.2 & 4.7 & L23 & 1.2 & 5.2 & 0.9 & 3.2 & 1.9 & 5.9 & 1.9 & 4.9 & 6.8 \\
Z Non-lesson related & 6.7 & 7.8 & 13.3 & 9.3 & 12.0 & 3.3 & 6.7 & 14.6 & 20.5 & 15.7 & 12.0 & 30.9 \\
$\quad$ behaviour & & & & & & & & & & & & \\
\hline
\end{tabular}

Table 1 summarizes the frequency of occurrence (expressed in percent) of individual behaviours by level and discipline. As shown in the table, instructors' behaviour in university science laboratories (expressed in percentages) is not consistent among disciplines and levels. The lack of uniformity in the behaviour of instructors in university science laboratories as shown in table 1 may be explained with the views expressed by (Kyle, Penicke \& Shymansky, 1980) that either (a) owing to the subject content differences between the science disciplines and levels, specific instructor behaviours and strategies are planned in advance and thus, the observed differences are the results of planned strategies relating to the purpose of each individual laboratory; or (b) instructors are randomly exhibiting behaviours in the laboratories based on situations that arise during the course of the laboratory session.

The table also showed that a reasonable amount of laboratory time is spent by most instructors transmitting information to students both within disciplines and between levels. The only exception was in Geology where the amount of time spent on transmission of information to students decreased from $56 \%$ in lower levels to $5.4 \%$ in higher levels. The table again showed that a reasonable percentage of the laboratory time was used by instructors to listen in Botany, Microbiology, Zoology and Chemistry both in within discipline and between levels. Physics and Geology instructors spent less than $10 \%$ of the laboratory time on listening.

Physics laboratory instructors spent ranges of between 12.2-14.1, 8.4-14.0, and 9.7-19.3 of laboratory time to Demonstrates Procedures; Active Observation; and Passive Observation respectively. The table again indicated that Geology laboratory instructors at the higher levels spent 26.1 and 30.9 of the laboratory time on Reading and/or writing and Non-lesson respectively. The table generally indicated that behaviours like: Asks extended thought questions, Asks factual recall questions and Demonstrate Procedures except for Physics; Gives directions, Positive reinforcement, Negative reinforcement, Acknowledges, and Moves except for Zoology at lower levels received low amount of the instructors' laboratory times. 
Table 2. Analysis of Individual Instructor Behaviour in University Science Laboratories

Behaviours

LEVEL (Df=l)
DEPARTMENT

$(d f=5)$

\begin{tabular}{|c|c|c|c|c|c|c|c|c|c|}
\hline & & $\begin{array}{l}\text { 差 } \\
\text { क्ञ } \\
\text { F- value }\end{array}$ & 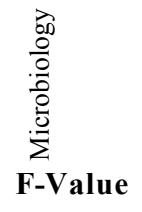 & $\begin{array}{l}\overrightarrow{0} \\
\stackrel{0}{0} \\
\stackrel{0}{0} \\
\stackrel{N}{\text { F-value }}\end{array}$ & 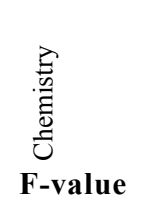 & $\begin{array}{l}\frac{\infty}{0} \\
\frac{0}{0} \\
\frac{2}{2} \\
\text { F-value }\end{array}$ & 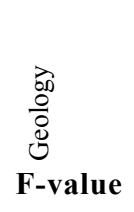 & F-value & $\operatorname{Pr}>\mathbf{F}$ \\
\hline $\mathrm{X}$ & $\begin{array}{l}\text { Asks extended } \\
\text { thought } \\
\text { questions }\end{array}$ & 0.001 & 0.628 & 3.947 & 0.628 & 2.455 & 0.500 & 4.093 & 0.004 \\
\hline Q & $\begin{array}{l}\text { Asks factual } \\
\text { recall questions }\end{array}$ & 1.831 & 2.027 & 0.037 & 0.540 & 0.600 & 0.600 & 4.563 & 0.002 \\
\hline D & $\begin{array}{l}\text { Demonstrates } \\
\text { procedures }\end{array}$ & 2.400 & 0.200 & 2.130 & 1.767 & 2.954 & 0.041 & 20.038 & 0.000 \\
\hline G & Gives direction & 1.929 & 0.001 & 2.885 & 1.107 & 0.005 & 1.316 & 32.935 & 0.000 \\
\hline S & Shows & 0.001 & 0.049 & 9.065 & 0.115 & 2.233 & 6.231 & 9.093 & 0.000 \\
\hline $\mathrm{T}$ & Transmits & 7.599 & 0.221 & 10.913 & 1.790 & 7.004 & 50.911 & 3.559 & 0.009 \\
\hline $\mathrm{P}$ & $\begin{array}{l}\text { Positive } \\
\text { reinforcement }\end{array}$ & 3.393 & 0.500 & 0.001 & 1,500 & 1.227 & 1.136 & 9.248 & 0.000 \\
\hline $\mathrm{N}$ & $\begin{array}{l}\text { Negative } \\
\text { reinforcement }\end{array}$ & 1.000 & 1.500 & 0.500 & 0.701 & 1.927 & 0.115 & 4.550 & 0.002 \\
\hline B & $\begin{array}{l}\text { Active } \\
\text { observation }\end{array}$ & 0.766 & 0.807 & 3.153 & 0.279 & 1.844 & 1.588 & 10.722 & 0.000 \\
\hline A & Acknowledges & 2.512 & 3.00 & 0.600 & $€ .333$ & 3.623 & 0.900 & 16.017 & 0.000 \\
\hline $\mathrm{L}$ & Listens & 1.786 & 1.767 & 0.004 & 7.014 & 0.018 & 0.545 & 25.679 & 0.000 \\
\hline $\mathrm{O}$ & $\begin{array}{l}\text { Passive } \\
\text { observation }\end{array}$ & 13.318 & 6.860 & 2.400 & 9.492 & 8.238 & .698 & 2.882 & 0.025 \\
\hline $\mathrm{R}$ & $\begin{array}{l}\text { Reads and/or } \\
\text { writes }\end{array}$ & $2.3 \mathrm{~L} 4$ & 4.371 & 1.500 & 13,035 & $0.3: 58$ & 21.814 & 7.172 & 0.000 \\
\hline M & Moves & $0.1 \mathrm{~L} 5$ & 1.962 & 10.881 & 3.1868 & 3.600 & 3.000 & 12.621 & 0.000 \\
\hline Z & $\begin{array}{l}\text { Non-lesson } \\
\text { related } \\
\text { behaviour }\end{array}$ & 3.340 & 7.51 & 7.004 & 2.440 & 0.01 & 27.160 & 3.831 & 0.006 \\
\hline
\end{tabular}


Table 2 showed that in Botany laboratory, instructors spent significantly different amount of class time on transmission of information and Passive Observation between lower and higher level classes. The post hoc analysis using a comparison of means in Table 1 showed that lower level Botany instructors spent more of the class time to transmit information than higher level instructors. The post hoc analysis also showed that higher level instructors spent more class time on Passive Observation than all other lower level instructors. The table also showed that for all other behaviours other than Transmit information and Passive Observation the instructors exhibited similar behaviours and no significant differences were found.

In Microbiology laboratory, the table showed that apart from Passive Observation and Non-lesson related behaviours where there were significant differences, all other instructor behaviours were not significantly different between lower and higher level classes. The direction of significance indicated that for Passive observation, and Non-lesson related behaviours, instructors in higher levels spent more of the class time on the behaviours than lower level instructors.

In Zoology laboratory, the table showed that there are significant differences in the class time spent between the higher and lower level instructors on: Shows, Transmits Information, Moves and Non-lesson related behaviours. The direction of significance by comparing means in table 1 indicated that lower level instructors spent more class time on Shows and Moves, while higher level instructors spent more time on Transmits and Non-lesson related behaviours. On the remaining behaviours no significant differences were found between the higher and lower level instructors.

In the chemistry laboratory, significant differences were found in behaviours like Listens, Passive Observation and Reads and/or Writes between higher and lower level instructors. The direction of significance indicated that in Passive Observation and Reads and/or Writes, instructors in lower levels spent more of the class time than higher levels instructors while in Listens, higher level instructors spent more of the class time than lower level instructors as shown in table 1. Apart from these three behaviors, no significant differences were found between the lower and higher levels instructors on the exhibition of the remaining laboratory behaviours.

Table 2 showed that in physics laboratory, lower and higher level instructors spent significantly different class time on Transmit information, and Passive Observation. The direction of significance using means in table 1 indicated that the lower level instructors spent more class time than higher level instructors on Transmit information while higher level instructors spent more time than lower level instructors on Passive Observation.

Table 2 also showed that in Geology laboratory, significant differences were found between lower and higher levels instructors on the exhibition of behaviours like Shows, Transmits information, Reads and/or Write and Non-lesson related behaviours. The direction of significance using means indicated that for Shows and Transmits information, lower level than higher level instructors spent more class time on them. While for Read and/or Write and Non-lesson related behaviours higher level instructors spent more time on them than the lower level instructors. For the remaining behaviours, no significant differences were found between the lower and higher levels instructors.

On specific instructor's behaviour in the six disciplines across the various categories of behaviours, table 2 showed significant differences among the instructors in all the categories of behaviour. All the calculated F-values were higher than the critical F-value of 2.400. With this result, $\mathrm{Ho}_{2}$ was therefore rejected.

\section{Discussion}

Ajaja (1998) while discussing the comments of (Kyle, Penick \& Shymansky, 1980) noted that the driving force of every science is research; and that is the investigation of nature to find closely connected facts and figures. In most cases, these investigations are done in the laboratories. To the scientists, the laboratory remains the most acceptable place to test a hypothesis before it is accepted as being right or wrong.

The findings of this study are most significant in the sense that they have provided a clear picture of what science laboratory instructors in the university do in the laboratories and how they spend the laboratory time considering the fact that they train science teachers for lower levels of education. The findings will therefore provide a pivot for improving science teaching and learning at all levels through policy guide lines on what behaviours should be most exhibited by science teachers during laboratory classes.

One of the findings of this study as shown in the observation mode, is that not enough of investigative kind of teaching goes on in most of the university science laboratories. This conclusion becomes very clear when you consider the amount of laboratory time instructors spent on activities like: Demonstrates Procedure, Shows, Transmits Information, Listens and Non-listening related behaviours. The bulk of the laboratory time is spent on these activities. Activities like; asks extended thought questions, asks factual questions, positive reinforcement, acknowledges student behaviour, and moves or gets supplies which would have enhanced investigative teaching received the least of 
instructional time. This finding agrees with the finding of Trowbridge and Bybee (1996) that in most science classes only between $2-3 \%$ of class time is oriented towards students' inquiry or investigation.

Inquiry or investigative science which is the recommended method for the effective science teaching and learning of science, is the process by which scientists pose questions about the natural world and seek answers. The investigative science done in the laboratories allows for deeper understanding, rather than knowing by authority or other processes (National Science Education Standards, 1991). Moyer, Hackett and Everett (2007) noted that teaching science effectively requires engaging students in inquiry. This suggests that school science teaching might be more in tune with the practice of science if it were taught in questioning mode using the laboratories rather than in the confirmation and expository mode that might be used in most of the university laboratories. Science instructors should design their laboratory classes to follow this procedure: (i) Asking questions, (ii) Asking students to state hypotheses, (iii) Asking students to design experiment to test stated hypotheses, (iv) Asking students to gather data and analyze the data to test stated hypotheses, and (v) Asking students to draw conclusions based on the analysis of data made.

The use of observational schedule rather than a rating scale tends to be a better way of determining the science teachers' effectiveness in the class. It remains doubtful if the science departments in Nigerian universities are well prepared and disposed to apply routine observation to improve laboratory instruction because of dearth of facilities in science laboratories. However, it is very necessary that instructors must first be aware of what they do and how they behave in their laboratories before they can then begin to think of ways in which to improve upon their instructions and interaction with students.

Among the six science disciplines the data collected and analyzed for each item, revealed significant differences for all the instructors behaviour. The findings suggest that for all the disciplines the instructors behave differently and in a very peculiar manner. The findings at this level tended to show the taxonomic characteristic behaviours of instructors in the various disciplines. The description of this situation is one issue whilst the explanation of why the situation is the way becomes individual explanation and interpretation. The multivaried interpretations that can be given to describe behaviours of instructors in various science disciplines can be resolved after a longitudinal study using a very large sample size.

\section{Conclusion}

Science laboratory behaviours of instructors in the university laboratories need to be monitored and well tailored if the students they train are to do the job of science teaching effectively and in a systematic way. One way of doing this, is the use of observational schedule to collect data on instructors behaviours in science laboratories. Accurate analysis of the feedbacks concerning the events and activities of instructors during a laboratory class is an essential first step towards improving science instructions.

The science laboratory interaction category used for this study, provided a very clear, easy to use and easy to understand alternative for determining the laboratory behaviour of instructors. This position is most valuable when it is known that the facts obtained gets directly at the actual processes of laboratory investigation and teaching rather than making an evaluator to infer from feelings or products provided to him. It is only when instructors conveniently know what they do in the laboratories that they can think of how to make changes and improve on their instructions. It is therefore concluded that the observation of what science instructors do in the university laboratories can be a source of reliable information on how to improve science teaching and learning at all levels since all categories of science teachers and instructors are trained in the university. The quality of their instructions in their institutions will depend on their training.

\section{Acknowledgement}

I wish to express my profound gratitude to all the laboratory instructors whose laboratory behaviours were coded for their cooperation and patience with the observers. I also wish to thank all the students involved for creating a conducive atmosphere for the observers to determine what goes on during laboratory instructions. I love you all.

\section{References}

Ajaja, O. P. (2005). An evaluation of differential effectiveness of Ausubel, Bruner and Karplus methods of teaching biology in Nigerian secondary schools. African Journal of Inter-Disciplinary Studies, 6(1\&2), 1-9.

Ajaja, O. P. (1998). An evaluation of differential effectiveness of Ausubel, Bruner and Karplus methods of teaching biology in Nigerian secondary schools. Unpublished Ph.D Thesis of University of Benin.

Bandura, A. (1977). Social Learning theory. Englewood, Cliffs, N. J: Prentice Hall.

Borich, C. B. (2004). Effective teaching methods. New Jersey: Pearson Merrill Prentice Hall. 
Brophy, J. (1989). Advances in research on teaching: Greenwich, C. T.: JAI Press.

Brophy, J. (2002). Teaching: Educational practices series. Retrieved May 7, 2009, from http//ww.theunesco.org

Brophy, J., \& Good, T. (1986). Teacher behaviour and student achievement. In M.C. Wittrock (Ed.). $3^{\text {rd }}$ Handbook of Research on Teaching, 328-375. Upper Saddle River, NJ: Merill Prentice Hall.

Comtrell, S. C. (1998/99). Effective teaching and literacy learning: A look inside primary classrooms. The Reading Teacher, 52(4), 370-378.

Dunkin, M., \& Biddle, B. (1974). The study of teaching. New York: Holt, Rinehart and Winston.

Johnson, B., \& Christensen, L. (2000). Educational research. Boston: Allyn and Bacon.

Kyle, W. C., Penick, J. E., \& Shymansky, J. A. (1980). Assessing and analyzing behaviour strategies of instructors in college science laboratories Journal of Research in Science Teaching, 17(2), 131-137. http://dx.doi.org/10.1002/tea.3660170207

Moyer, R. H. Hackett, J. K., \& Everett, S. A. (2007). Teaching science as investigations: Modeling inquiry through learning cycle lessons. New Jersey: Peason Merill Prentice Hall.

National Science Education Standards. (1991). A Sampler. Washington, D.C: National Research Council.

Rosenshine, B. (1971). Teaching behaviours and students achievement. London: National Foundation for Educational Research in England and Wales.

Shymansky, J. A., \& Penick, J. E. (1979). Use of systematic observation to improve college science laboratory instruction. Science Education, 63(2), 195-203. http://dx.doi.org/10.1002/sce.3730630207

Taylor, B.M., Pearson, P. D, Clark, K. F., \& Walpole, S. (1999). Effective schools accomplished teachers. The Reading Teacher, 53(2), 156-159.

Teddlie, C., \& Stringfield, S. (1993). Schools make a difference: Lessons learned from a 10 year study of school effects. New York: Teacher College Press.

Thorndike, R. L., \& Hagen, E. P. (1997). Measurement and evaluation in psychology and education. Upper Saddle River, NJ: Prentice Hall.

Trowbridge, L. W., \& Bybee, R. W. (1996). Teaching secondary school sciences; strategies for developing scientific literacy. New Jersey: Merill Prentice Hall.

Wiseman, D. C. (1999). Research strategies for evaluation. New York: Wadsworth Publishing Company.

\section{Appendix}

Appendix 1

\section{Science Laboratory Interaction Categories}

\section{$\underline{(\mathrm{SL} 1 \mathrm{C})}$}

The research work which calls for this checklist is purely academic in purpose and it is aimed at finding out laboratory behaviours of science instructors to improve instruction in science courses in Delta State University, Abraka.

\section{Instructions to Observers}

a. Fill in the spaces provided by writing.

b. During the lesson, make a mark next to the appropriate category every five seconds.

c. After the lesson, mark the frequency of occurrence of the categories according to your marks during the lesson.

d. Using the following scale (ties are allowed)

a. If the behaviour was the dominant one, mark 4 .

b. If the behaviour was quite frequent, mark 3 .

c. If the behaviour was infrequent, mark 2 .

d. If the behaviour did not occur, mark 1 .

e. Fill in the sheet without consulting anyone, and hand it immediately to the researcher.

Thanks for your cooperation.

Personal Data: 
1) Sex:

2) Name of the Department:

3) Course Instructed:.

\section{Categories}

$\mathrm{X}$ Asks extended thought question; requires students to synthesize ideas; includes question designed to elicit predictions, hypotheses, explanations, or evaluations.

Q Ask factual recall question; no student synthesis required, includes questions asked for descriptions of what was done or happened.

D Demonstrates Procedure; any teacher manipulation to tell the student what to do or how to do an activity.

G Gives Direction; verbal behaviours which tell the student what to do or how to do, designed to redirect student behaviour.

S Shows illustrates; any teacher manipulation of equipment done for the purpose of transmitting non-directive information (not designed to tell students what to do or how to do an activity).

$\mathrm{T}$ Transmits information; verbally transmitted non-directive information without the use of manipulative materials.

P Positive-reinforcement: positive evaluation of student behavior

$\mathrm{N}$ Negative reinforcement: negative evaluation of student behaviour

B Active Observation; receiving information from the student through the direct manipulation of or references to material or object

A Acknowledges student behaviour; non-evaluative statements or gestures used to indicate attentiveness to student behaviour, includes repeating or rephrasing student response.

L Listens to student; receiving information from student through discourse directed at the teacher.

O Passive observation; watching or listening to students in situations where teacher is not directly or actively involved.

$\mathrm{R}$ Reads and/or writes; any lesson related reading or writing done by the teacher, with or without students directly involved.

M Get supplies; procurement of materials for use in the laboratory

Z Non-lesson-related behaviours; any teacher behaviour which does not facilitate the activities or lesson taught.

\section{Note}

Note 1. Developed by J. A. Shymansky, J.E. Penick, L.J. Kelsey, \& G.W. Foster of the Science Education Center, University of Iowa (1977). Source: Shymansky, J.A. \& Penick, J.E. (1979). Science Education, 63(2), 195-203. 